\title{
Resultados Geofísicos Integrados de um Corpo com Geometria 3D sem Manifestação Superficial
}

\author{
André Rugenski (andrerug@iag.usp.br), Marta Silvia Maria Mantovani, \\ Liliana Alcatraz Diogo, Wladimir Shukowsky \\ Instituto de Astronomia, Geofísica e Ciências Atmosféricas - USP \\ R. do Matão 1226, CEP 05508-900, São Paulo, SP, BRA \\ Recebido em 16 de dezembro de 2004; aceito em 09 de junho de 2005
}

Palavras-chave: intrusão alcalina, Registro - SP, levantamentos geofísicos.

\section{RESUMO}

O levantamento aerogeofísico SP-RJ do Serviço Geológico do Brasil (CPRM) evidencia uma anomalia magnética, sem correspondentes geológicos em superfície, mas com feições semelhantes àquelas observadas para os complexos alcalinos que afloram na mesma região. Diante da ausência de elementos superficiais, foram utilizadas diferentes técnicas geofísicas para caracterizar a fonte dessa anomalia. Entre as diferentes metodologias, utilizou-se a análise de imagens de satélite para diferentes bandas espectrais, sondagens sísmicas, levantamento gravimétrico e correspondente magnético em superfície ao longo de um perfil que corta a anomalia, além de medidas de densidade e susceptibilidade das diferentes litologias da área. As informações resultantes da aplicação dessas técnicas serviram como vínculos para modelar simultaneamente os dados gravimétricos e magnéticos de superfície com geometria $2 \frac{1}{2} \mathrm{D}$, e para modelar os dados magnéticos do levantamento aéreo com geometria 3D. Os resultados obtidos convergem para um corpo intrusivo máfico de cerca $3,3 \times 10^{9} \mathrm{t}$, próximo da superfície ( $\sim 40 \mathrm{~m})$ e estendendo-se até a profundidade máxima de $1 \mathrm{~km}$.

Keywords: alkaline magmatism, Registro - SP, geophysical surveys.

\begin{abstract}
Airborne geophysical data of the SP-RJ survey carried out by the Brazilian Geological Survey (CPRM) reveal a magnetic anomaly without geological expression at the surface. The anomalous features are similar to those associated with alkaline complexes that outcrop in the same region. The absence of surface elements motivated the use of different geophysical methods to characterize the magnetic anomaly source. Among these methods, satellite images for different spectral bands were used, seismic sounding, gravity and ground magnetic surveys along a profile crossing the anomaly were performed, and density and susceptibility measurements of different rock types in the area were made. The obtained results were used to constrain $2 \frac{1}{2} \mathrm{D}$ simultaneous gravity and magnetic modeling and $3 \mathrm{D}$ airborne magnetic modeling. Both results indicate the presence of a body of about $3.3 \times 10^{9}$ metric tons, having its top at 40 meters from the surface and extending to a maximum depth of $1 \mathrm{~km}$.
\end{abstract}




\section{INTRODUÇÃO}

Na subárea 3 do levantamento aeromagnético do Serviço Geológico do Brasil (CPRM), na posição $47,7142^{\circ} \mathrm{W}$ e $24,5401^{\circ} \mathrm{S}$, observa-se uma anomalia magnética de polarização normal, sem qualquer correspondente geológico (Ferreira e Algarte, 1979). Essa anomalia encontra-se inserida na Província Alcalina do Arco de Ponta Grossa (Almeida, 1983), mais especificamente, nas proximidades dos Complexos Alcalinos de Juquiá, Jacupiranga, Pariquera-Açú e Cananéia. O alojamento desses complexos ocorreu entre 130 e $82 \mathrm{Ma}$, idades estimadas pelo método K-Ar (Gomes e Cordani, 1965; Amaral et al., 1967; Born et al., 1971; Amaral, 1978; Morbidelli et al., 1995). A maioria dessas rochas alcalinas apresenta afinidade potássica sendo que os dois primeiros complexos citados têm associação com carbonatitos (Gomes et al., 1996). Com exceção do Complexo de Jacupiranga, cuja complexidade não permite discriminar a direção de polarização predominante do Complexo, as demais também apresentam polarização normal.

No local da anomalia são observados sedimentos colúvio-aluvionares do Rio Ribeira do Iguape. A área é alagada e, portanto, de difícil acesso para fins de levantamentos geofísicos de precisão. A ausência de um detalhamento geológico sobre essa área, induziu a utilização de metodologias geofísicas, como a análise de imagens de satélite (Landsat) de forma qualitativa, visando o reconhecimento do local (compondo as bandas 3, 2, 1 do espectro visível vermelho verde e azul), a definição das regiões alagadas (banda 4 do espectro infravermelho), a geomorfologia e correspondente litologia (bandas 3, 4 e 7 do espectro vermelho, infravermelho próximo e infravermelho afastado), e a densidade da vegetação (bandas 4,3 e 2 do espectro infravermelho próximo, vermelho e verde).

Com o intuito de limitar o número de soluções possíveis nas modelagens dos campos potenciais (magnético e gravitacional), investigou-se a aplicabilidade dos métodos sísmicos na área de estudo, para a estimativa da profundidade do topo do corpo intrusivo, bem como para a determinação dos valores de densidade dos meios. Estes estimados com base nos valores de velocidade das ondas sísmicas. Foram realizados ensaios sísmicos para análise de ruído (walkway noise test) em três locais selecionados a partir da resposta magnética em superfície.

Para identificar as características geométricas do corpo responsável pela anomalia magnética observada e comparálo com os demais complexos alcalinos, foi efetuado um levantamento gravimétrico sobre um perfil que cruza a anomalia magnética. Sobre o mesmo perfil, foram também efetuadas medidas magnéticas de superfície com o propósito de refinar a informação proveniente do levantamento aéreo e possibilitar uma análise conjunta dos sinais gravimétrico e magnético sobre o perfil. Foram realizadas também medidas de susceptibilidade magnética em amostras de sedimentos da região como complementação àquelas obtidas para corpos alcalinos aflorantes na área e disponíveis em literatura.

Apresentam-se em seguida os detalhes dos diversos levantamentos geofísicos, os resultados obtidos e a sua interpretação.

\section{BASE DE DADOS GEOFÍSICOS}

\section{Imagens aerogeofísicas e de satélite}

A localização da área de estudo juntamente com o mapa magnético em tons de cinza, próxima da cidade de Registro, é mostrada na Figura 1a, e o detalhe da anomalia magnética de Registro representada por linhas de contorno, na Figura 1b. Essas imagens foram obtidas utilizando os dados aeromagnéticos do Projeto geofísico São Paulo - Rio de Janeiro. A área foi sobrevoada entre 1978 e 1979 pela Encal sob contrato da então Companhia de Pesquisa de Recursos Minerais (CPRM), atualmente Serviço Geológico do Brasil. As Linhas de vôo com direção $\mathrm{N}-\mathrm{S}$ e espaçamento de $1 \mathrm{~km}$, registraram medidas do campo magnético total e as linhas de controle (E-W) cruzaram as linhas de vôo a intervalos de $10 \mathrm{~km}$. Todas as medidas foram reduzidas à altura nominal de vôo de $150 \mathrm{~m}$ sobre o nível do solo. As medidas foram efetuadas com um magnetômetro de precessão de prótons e o registro magnético disponibilizado já estava corrigido da variação diurna e com o campo geomagnético de referência (IGRF) calculado para a época do levantamento removido (Anjos e Mourão, 1988). Na Figura 1a, a anomalia de interesse está indicada como 2; notam-se claramente os diques máficos no Arco de Ponta Grossa, com direção WNW-ESSE e a direção dos lineamentos Guapiara e São Gerônimo-Curiúva ao sul das estruturas. A Figura 1c, mostra o acesso para o local do levantamento.

As imagens de satélite analisadas foram extraídas do banco de imagens do satélite Landsat 5. A Figura 2a mostra uma combinação das bandas 3, 2 e 1 do espectro visível. A imagem está na composição RGB (vermelho, verde, azul), equivalente a uma foto aérea. Notam-se claramente os meandros do Rio Ribeira de Iguape, a vegetação em tons de cinza claro a preto, as estradas de acesso (linhas brancas) e depósitos de areia sem vegetação (regiões brancas da imagem). Seja nessa representação, como para outras combinações de bandas de freqüência (3, 4, 2; Figura 2b), observa-se claramente uma estrutura oval, quase circular (indicada pela letra C), em correspondência à porção positiva da anomalia magnética. Sua localização é facilmente resgatável pela posição dos meandros. 


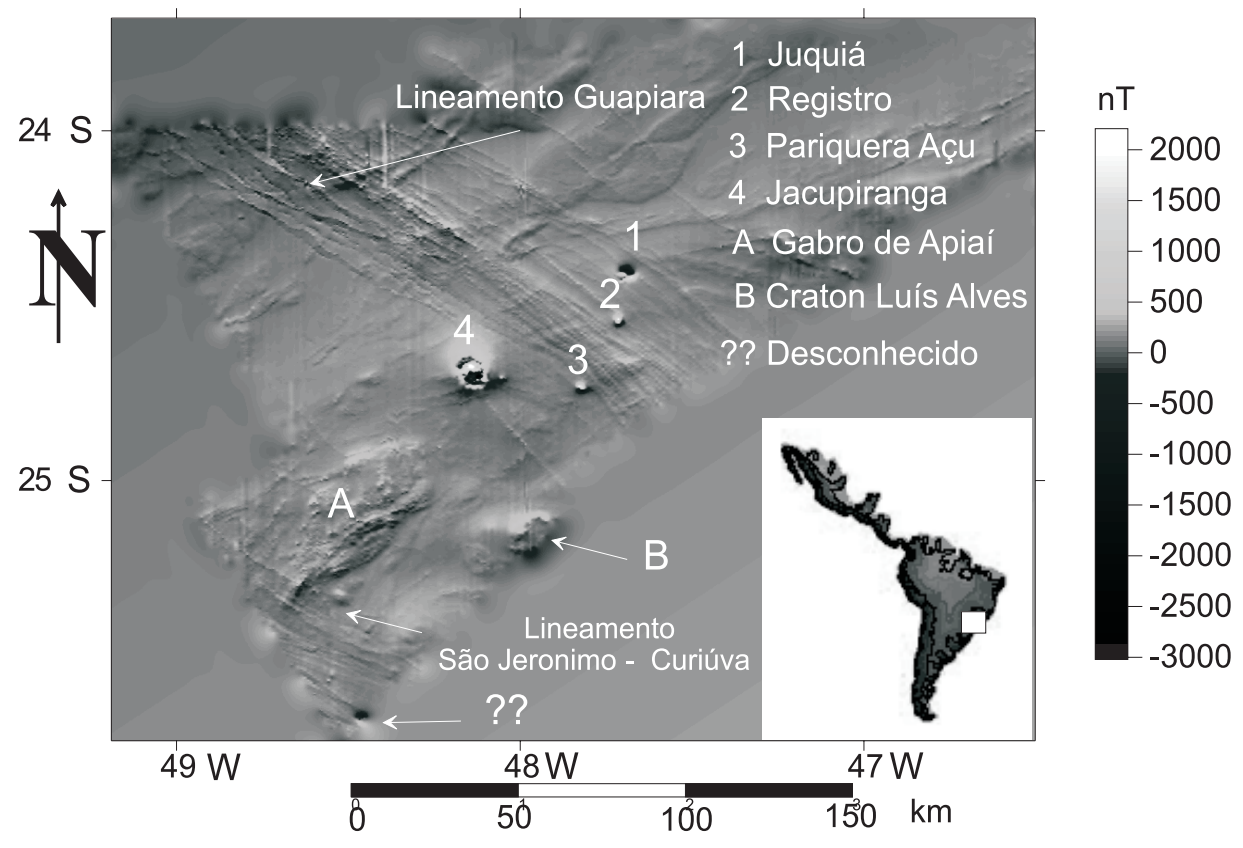

Figura 1a. Representação da resposta magnética do levantamento aéreo São Paulo - Rio de Janeiro, subáreas 3 e 4.

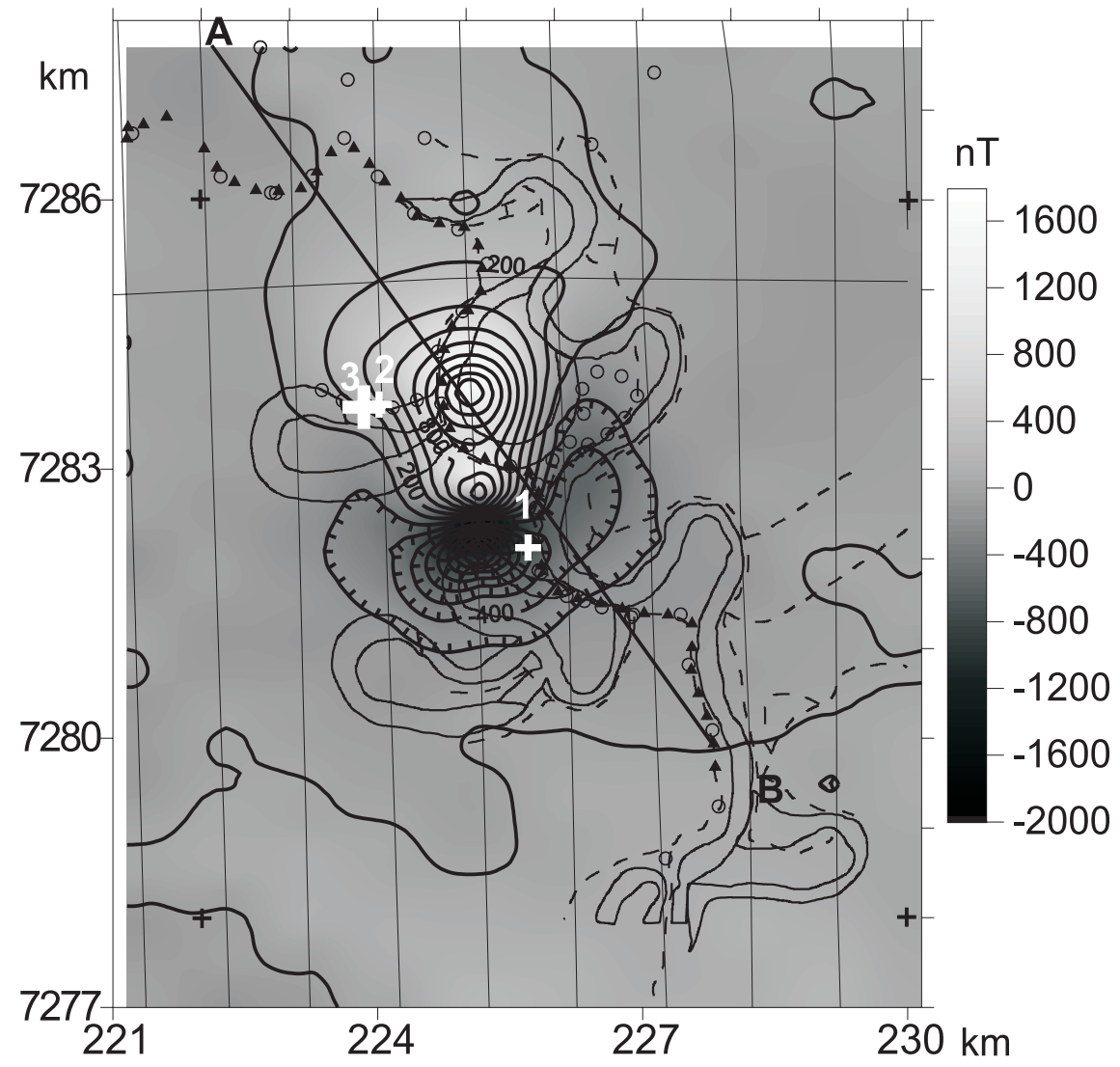

Figura 1b. Representação da anomalia observada através dos dados aeromagnéticos, superposta às linhas de vôo (N-S) e de controle (E-W); localização das estações gravimétricas (círculos) ao longo das vias de acesso; localização dos testes sísmicos rasos (cruzes brancas); localização das estações magnéticas (triângulos); percurso em meandros, do Rio Ribeira do lguape (linhas pretas finas). 


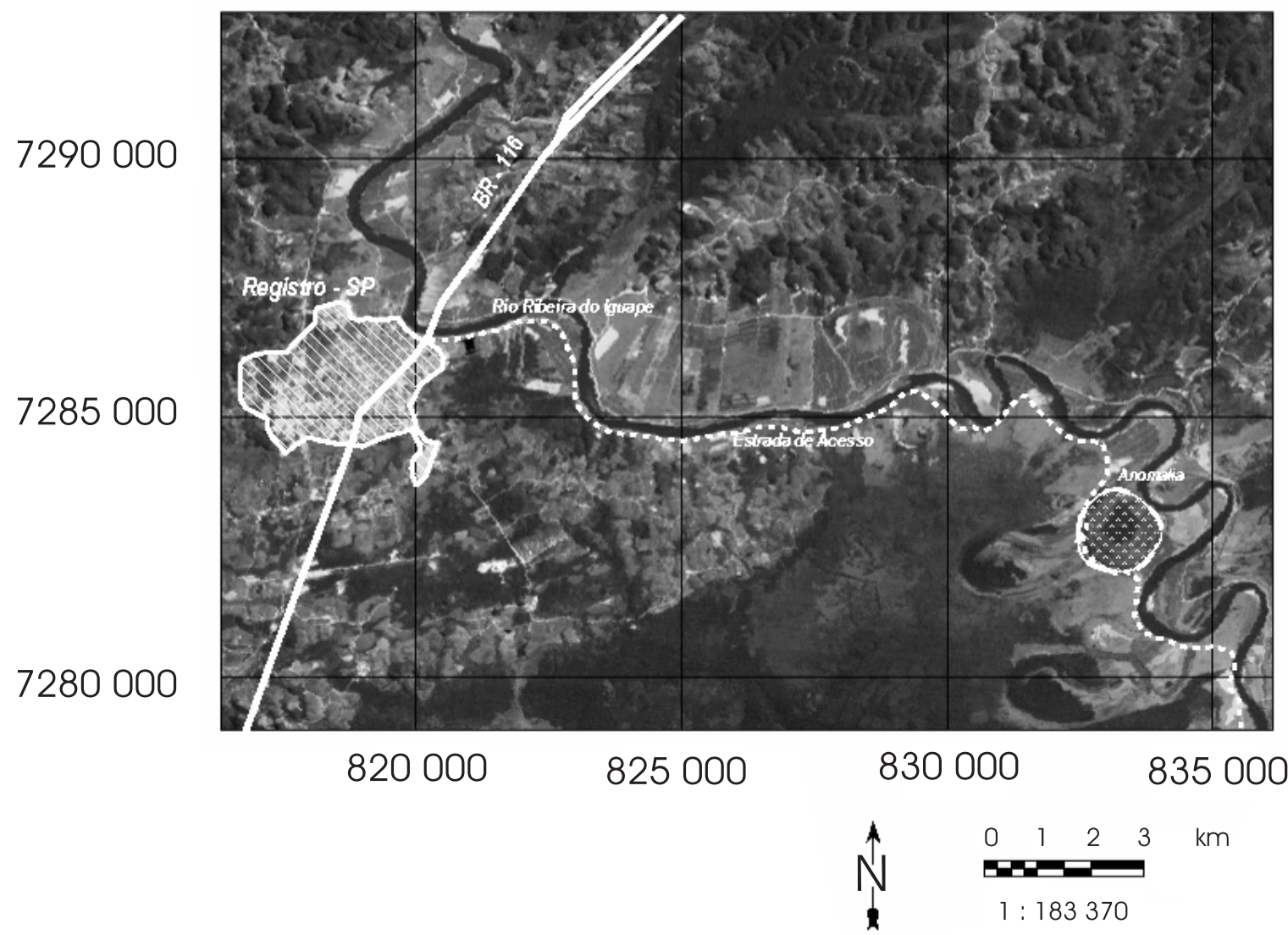

Figura 1c. Estradas de acesso à região de estudo (linhas brancas sólidas - BR116 e tracejada acompanhando o Rio Ribeira de Iguape). As coordenadas em (b) e (c) estão no sistema UTM, tendo como Meridiano Central -45 e modelo do Geóide SAD69.

\section{Sísmica rasa}

Com o intuito de determinar a velocidade das ondas sísmicas através das diferentes litologias para estimar suas densidades relativas e a profundidade do topo do corpo que produz a anomalia magnética, foram efetuados três ensaios sísmicos para a análise de ruído, cujas localizações são apresentadas na Figura 1b. O teste (1) localiza-se sobre a porção negativa da anomalia magnética, em correspondência às coordenadas UTM $(225,703 ; 7282,124) \mathrm{km}$, (calculadas para o modelo SAD69 e meridiano central -45), enquanto que os outros dois ensaios (2) e (3) foram feitos mais ao norte, na porção positiva da anomalia magnética, em correspondência às coordenadas UTM $(224,015 ; 7283,719) \mathrm{km}$.

Os registros sísmicos foram adquiridos com o sismógrafo digital de 24 canais da OYO-Geospace. Como fonte de energia utilizou-se uma marreta batida sobre placa de metal. Nos ensaios (1) e (2) foram empregados geofones com freqüência natural de $100 \mathrm{~Hz}$ para avaliar a possibilidade de identificar as reflexões. Já no ensaio (3), cujo principal objetivo foram as refrações, utilizaram-se geofones de $28 \mathrm{~Hz}$. Em todos os registros o intervalo de amostragem foi de $0,125 \mathrm{~ms}$.

O "walkway noise test" (1) foi adquirido movendo-se o ponto de tiro, mantendo fixos os geofones espaçados de $1 \mathrm{~m}$. Foram executados 4 pontos de tiro, a intervalos de $24 \mathrm{~m}$, originando um registro com afastamento máximo de $96 \mathrm{~m}$. Da análise das primeiras quebras, obteve-se uma velocidade de $0,4 \mathrm{~km} / \mathrm{s}$ para a onda direta, $1 \mathrm{~km} / \mathrm{s}$ para a primeira refração e $1,5 \mathrm{~km} / \mathrm{s}$ para a segunda refração. Essas velocidades da onda $\mathrm{P}$, relativamente baixas, sugerem a ausência de rochas ígneas ou do embasamento próximo da superfície, até $20 \mathrm{~m}$ de profundidade. Para as rochas objeto do estudo esperase velocidade superior a $3 \mathrm{~km} / \mathrm{s}$.

Para o teste 2, empregou-se um afastamento entre geofones de $2 \mathrm{~m}$, tendo-se efetuado dois pontos de tiro a intervalos de $48 \mathrm{~m}$. Os registros são apresentados na Figura 3. A análise das primeiras quebras forneceu uma velocidade de $0,4 \mathrm{~km} / \mathrm{s}$ para a onda direta, $1,5 \mathrm{~km} / \mathrm{s}$ para a primeira refração e $4,0 \mathrm{~km} / \mathrm{s}$ para a segunda refração. A velocidade da segunda refração sugere a ocorrência de uma rocha mais densa 


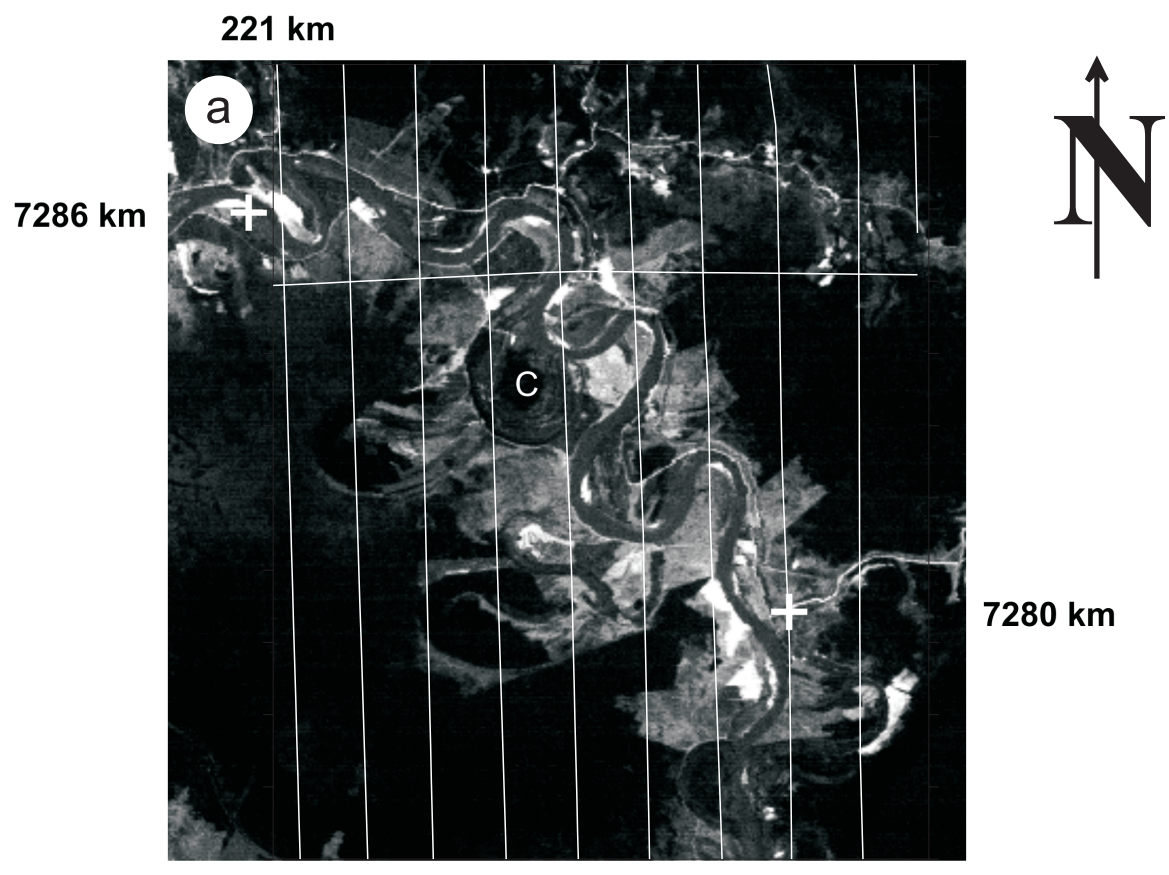

$228 \mathrm{~km}$
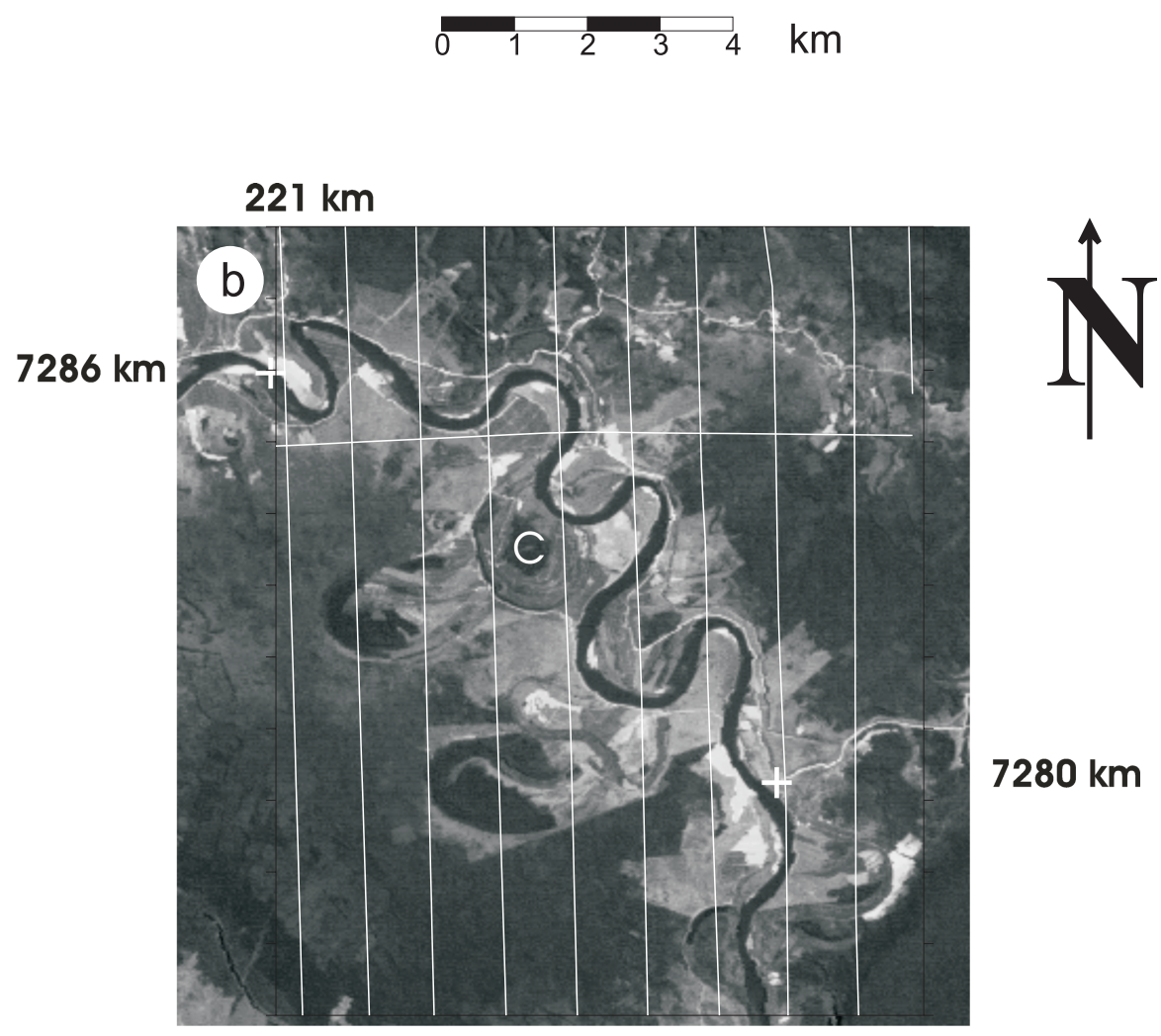

$7280 \mathrm{~km}$
Figura 2. a) Visualização da região de estudo na mesma escala da Figura 1b, na composição espectral 3, 2 e 1 (RGB). b) Densidade da vegetação e depósitos aluvionares (bandas 3, 4 e 2 do espectro vermelho, infravermelho próximo e verde). O símbolo " $\mathrm{C}$ " corresponde ao centro da anomalia produzida por um corpo subsuperficial aparentemente "quasecircular".

$228 \mathrm{~km}$

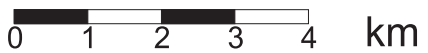


(ígnea), podendo ser interpretada como intrusão alcalina.

Para o ensaio (3), cujo principal objetivo foi a análise das refrações efetuou-se dois pontos de tiro, um em cada extremo (sentidos direto e reverso) do arranjo de 24 geofones espaçados de $10 \mathrm{~m}$ (Figura 4). As velocidades obtidas foram de $0,5 \mathrm{~km} / \mathrm{s}$ para a onda direta, nos dois registros; $1,38 \mathrm{~km} / \mathrm{s}$ e $4,0 \mathrm{~km} / \mathrm{s}$, respectivamente, para a primeira e segunda refração no sentido direto, e $1,65 \mathrm{~km} / \mathrm{s}$ e $6,3 \mathrm{~km} / \mathrm{s}$, respectivamente, para a primeira e segunda refração no sentido reverso. Através do método do tempo de interseção foi estimado um valor médio para a profundidade do topo do corpo ígneo em $40 \mathrm{~m}$.

Através das velocidades observadas para as ondas sísmicas foram estimadas as densidades $(\rho)$ dos meios. Para as formações sedimentares foi utilizada a relação de Gardner et al. (1974), $\rho=0,31 . V_{p}^{0,25}$, sendo a velocidade da onda $\mathrm{P}$ $\left(V_{P}\right)$ dada em $\mathrm{m} / \mathrm{s}$ e a densidade em $\mathrm{g} / \mathrm{cm}^{3}$. Para $\left(V_{P}\right)$ foi assumido um valor médio representando o pacote acima do topo rochoso, resultando em um valor para a densidade de $\rho=1,70 \pm 0,07 \mathrm{~g} / \mathrm{cm}^{3}$.

Para o corpo ígneo, considerou-se a relação:

$$
\rho=\frac{7}{2} \frac{\mu}{V_{P}^{2}} \mathrm{~g} / \mathrm{cm}^{3} \text { (Cérmak e Huckenholz, 1982). }
$$

Uma vez que o valor da densidade é aproximadamente conhecido para cada tipo de rocha, a análise da razão entre o módulo de rigidez e a velocidade da onda $\mathrm{P}$ permite tecer considerações sobre as características elásticas no segmento de crosta onde se efetuou o teste.

Considerando-se o valor tabelado da constante de Poisson $\boldsymbol{V}=0,3$ (valor médio para o piroxenito) e o módulo de rigidez $\mu=55,2 \mathrm{GPa}$ (segundo Cérmak e Huckenholz, 1982), mesmo tomando-se um valor elevado para
$V_{P}=6,3 \mathrm{~km} / \mathrm{s}$, o valor obtido para a densidade $\left(\rho \cong 4,95 \mathrm{~g} / \mathrm{cm}^{3}\right)$ estaria superestimado em relação ao valor $\rho \cong 3,14 \mathrm{~g} / \mathrm{cm}^{3}$ medido em amostras de piroxenito na área da anomalia de Juquiá (Slavec et al., 2001). Entretanto, se ao módulo de rigidez for atribuído um valor de $\mu=35,0 \mathrm{GPa}$, obtém-se um valor de densidade compatível com aquele medido por Slavec et al. (2001). Neste caso, uma vez comprovada a existência da rocha alcalina, sua porção superior (topo) deverá estar fortemente intemperizada.

\section{Gravimetria}

O levantamento gravimétrico, para o propósito deste trabalho, foi realizado ao longo de um perfil que cruza a anomalia magnética segundo seu eixo maior, na direção aproximadamente NWN-SES. Não foi possível realizar um levantamento de superfície, ou utilizar vários perfis, diante da dificuldade de acesso na área. $\mathrm{O}$ espaçamento médio entre pontos consecutivos foi de aproximadamente $500 \mathrm{~m}$ na parte central do levantamento, aumentando gradativamente para pontos mais afastados.

As medidas de aceleração da gravidade $(\mathrm{g})$ foram efetuadas com o gravímetro LaCoste e Romberg modelo "G", n 996, dotado de "feedback" analógico, leitura e níveis eletrônicos. O dispositivo denominado "feedback" (realimentação), compensa eletronicamente o deslocamento da massa interna do gravímetro, mantendo-a na posição de desvio nulo relativamente ao ponto de equilíbrio. A força eletromagnética aplicada para realizar essa compensação é convertida em unidades de g e lida num visor digital, fornecendo a parcela centesimal da leitura convencional, sendo esta última feita no disco de leitura da compensação

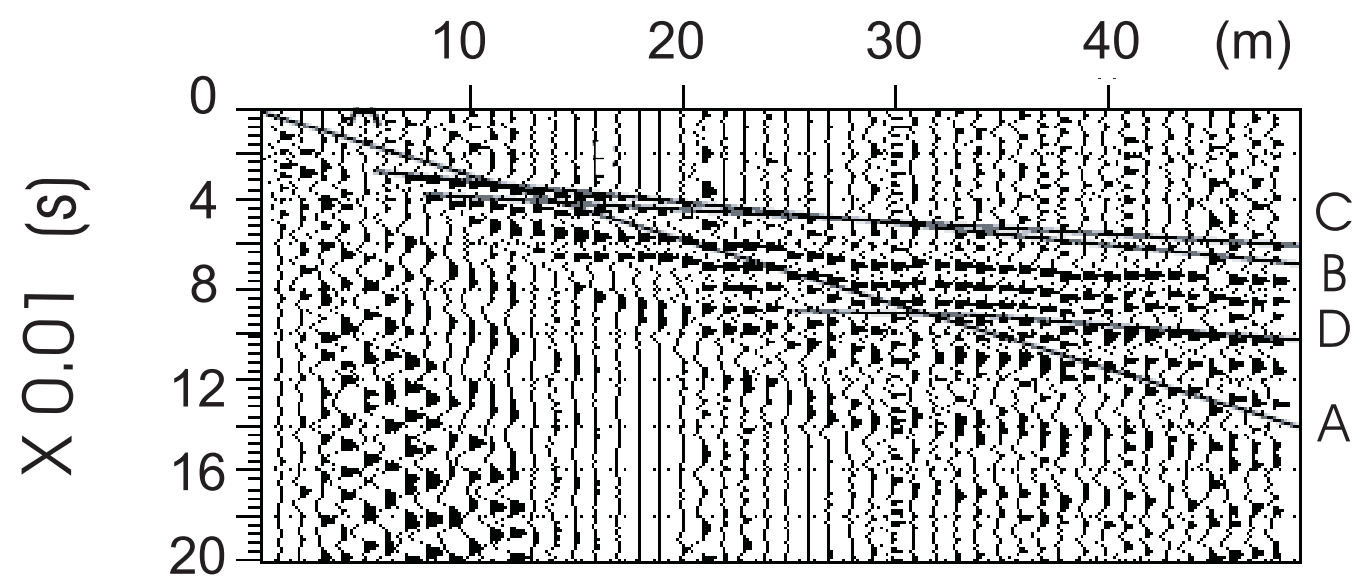

Figura 3. Sismograma do ensaio (2): observam-se as ondas diretas (A), a primeira refração (B), a segunda refração $(C)$ e o sinal interpretado como sendo a reflexão no topo do corpo ígneo (D). 


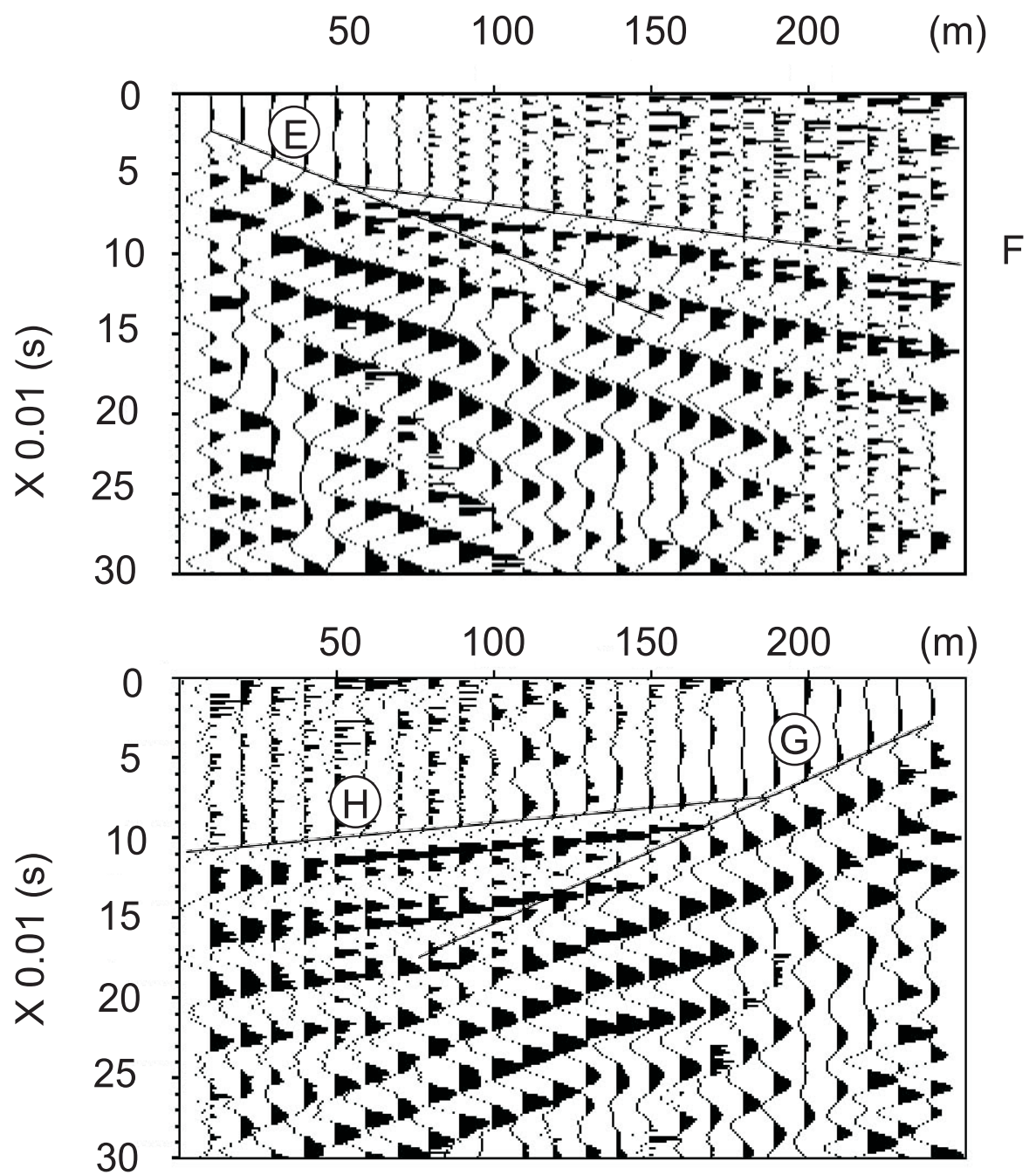

Figura 4. Sismograma direto e reverso do ensaio (3) ("end on array"); as refrações foram identificadas como primeira refração $(E)$, segunda refração $(F)$, primeira refração revertida $(G)$ e segunda refração revertida $(H)$. A diferença nas velocidades de $(F)$ e $(H)$ sugerem a presença de um refrator inclinado.

mecânica. Sua utilização permite uma maior precisão $(0,01 \mathrm{mGal})$, da ordem de 10 vezes da medida de g efetuada sem o "feedback". Com os níveis eletrônicos é possível refinar o posicionamento feito com os níveis de bolha para manter o gravímetro na posição mais próxima da vertical (Figura 5).

Todas as medidas foram referidas à estação da rede gravimétrica fundamental brasileira: "Ribeira B" (código: $121382 ; \mathrm{g}=978835,742 \pm 0,012 \mathrm{mGal}$ ) cuja altitude é fornecida pelo RN 2113-S ( $\mathrm{h}=167,6861 \mathrm{~m}, \mathrm{snm})$, nas coordenadas de longitude $=-49^{\circ} 00^{\prime} 24^{\prime \prime}$ e latitude $=-24^{\circ} 39^{\prime} 18^{\prime \prime}$ (valores fornecidos pelo Observatório Nacional (ON) e pelo Instituto Brasileiro de Geografia Estatística (IBGE) nos endereços eletrônicos): a. http://www.on.br/institucional/geofísica/areapage/ gravimetria/rgfbabs.html

b. http://www.ibge.gov.br/Banco_de_Dados_Geodesicos

A redução das medidas gravimétricas levou em conta as correções de Maré Sólida (Longman, 1959), de ar-livre ou Faye (elevação em relação à superfície do geóide), e de Bouguer (efeito das massas topográficas interpostas). Em vista da regularidade da topografia na área de estudo, não foram adicionadas as correções de terreno (Gemael, 2002). O cálculo da anomalia gravimétrica utilizou o valor teórico de $\mathrm{g}$ obtido pela Fórmula Internacional da Gravidade de 1967:

$g=978,03090\left(1+0,005302 \operatorname{sen}^{2} \theta-0,5828 \times 10^{-5} \operatorname{sen}^{2} 2 \theta\right)$ 

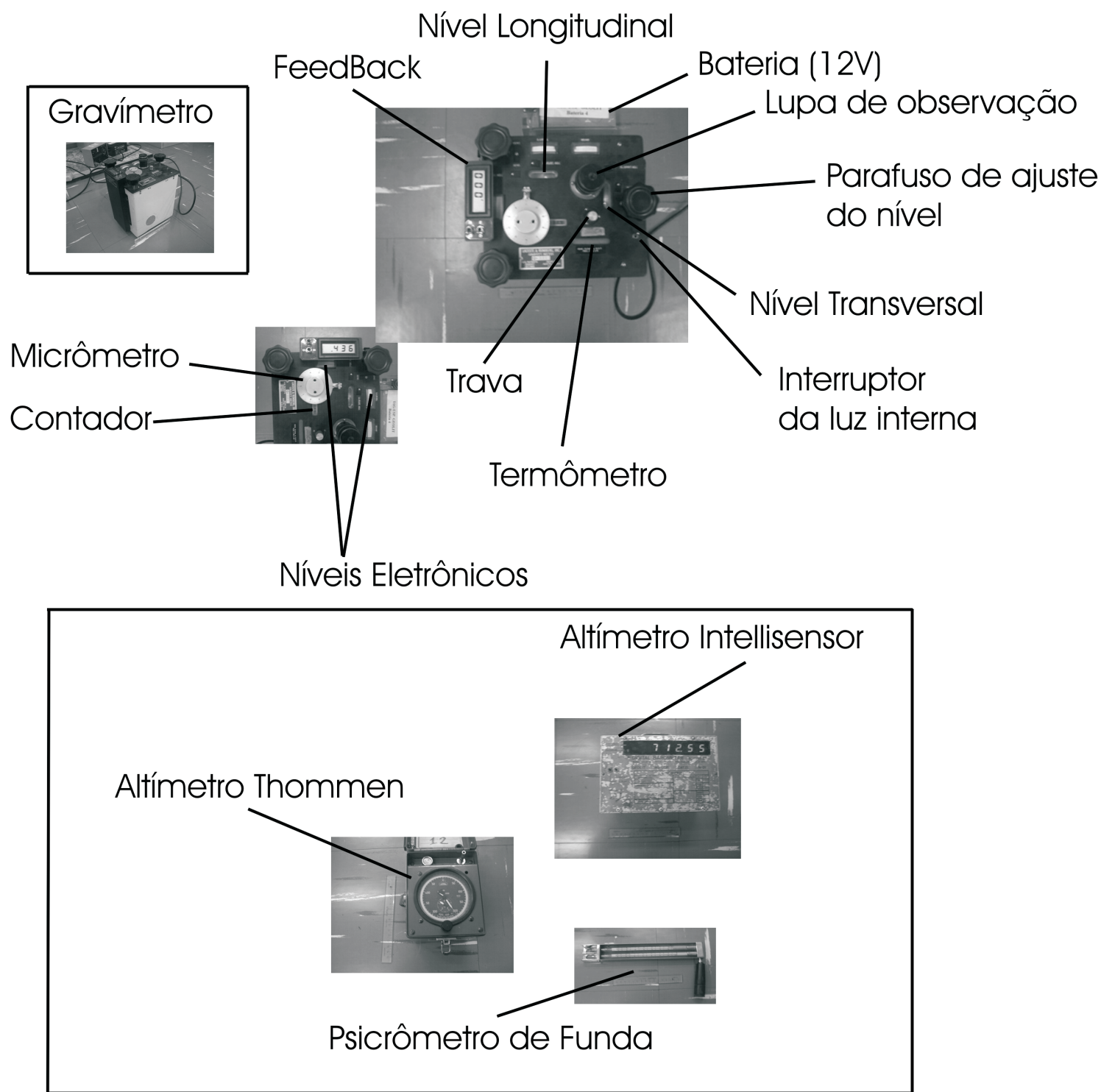

Figura 5. Foto do gravímetro G-996, mostrando o disco de leitura com nanômetro (Dial), o realimentador analógico (feedback), as leituras eletrônicas da massa e dos níveis, os parafusos de ajuste dos níveis, termômetro e lupa de observação. A trava é utilizada sempre que se transporta o gravímetro, e o interruptor ativa a energia luminosa (lupa) e das leituras eletrônicas (massa e níveis). A leitura do termômetro é utilizada para verificar se o gravímetro mantém a temperatura de observação durante todo o período de medida. O aquecimento é feito através da bateria (previamente carregada) que acompanha o equipamento nos deslocamentos. Abaixo, observam-se o altímetro analógico (Thommen), o altímetro eletrônico (Intellisensor) e o psicrômetro de funda. Os dois termômetros que compõem o psicrômetro se diferenciam por ter o bulbo um, umedecido, e o outro, seco, permitindo fazer a medida de umidade do ar, utilizada nas correções de altimetria por barometria entre a base e a estação móvel. 
onde $\theta$ é a latitude no ponto de medida.

As 51 medidas gravimétricas, efetuadas ao longo das vias de acesso à área, foram projetadas sobre o perfil $\mathrm{AB}$ (Figura 1b). Observam-se, na mesma figura, as linhas de vôo, com direção N-S, do levantamento aéreo (Anjos e Mourão, 1988), o contorno da anomalia magnética extraída dos dados aeromagnéticos, com amplitude máxima de $2400 \mathrm{nT}$, e os meandros traçados pelo Rio Ribeira do Iguape. As coordenadas UTM, expressas em km, são referidas ao meridiano central -45 e ao modelo de geóide SAD69.

\section{Magnetometria}

Ao longo das mesmas vias de acesso, percorridas para o levantamento gravimétrico, foram efetuadas 50 medidas de magnetometria de superfície, com o intuito de melhor utilizar a informação do levantamento aéreo. As medidas foram realizadas com um magnetômetro de precessão de prótons, marca Terraplus e modelo Overhauser GSM19, sendo o espaçamento médio entre dois pontos consecutivos na região da anomalia de cerca $500 \mathrm{~m}$. O processo de medida utilizou magnetômetro em uma base fixa, de mesma marca e modelo daquele móvel. A leitura foi feita a cada 1 min. Eliminou-se o Campo Geomagnético de Referência Internacional (IGRF), calculado após a correção qüinqüenal (DGRF), do campo total medido. Os pontos de medida são indicados por triângulos na Figura $1 \mathrm{~b}$.

\section{Coordenadas}

\section{Planimetria}

As coordenadas planimétricas em cada ponto foram determinadas através de um receptor de posicionamento por satélite (GPS) de marca Trimble, modelo Basic. Esse mesmo equipamento foi utilizado para fins de navegação durante os levantamentos geofísicos e na localização dos pontos de coleta das amostras. A precisão na localização de cada ponto, variável entre $15 \mathrm{~m}$ e $50 \mathrm{~m}$ dependendo da constelação de satélites disponíveis no instante da medida, implica numa incerteza inferior a $0,1 \mathrm{mGal}$, para essa latitude, quando propagado para o valor da aceleração da gravidade.

\section{Altimetria}

A elevação topográfica em cada ponto de medida gravimétrica e magnética foi determinada pelo método barométrico com base fixa. Vários testes demonstraram que a utilização da base fixa, num raio inferior a $30 \mathrm{~km}$ e com desnível topográfico inferior a $100 \mathrm{~m}$, entre a base e o ponto de medida, permite limitar os erros a valores máximos inferiores a 1,2 m, que representam menos de $0,4 \mathrm{mGal}$ no cálculo de g. A distribuição dos erros tem como desvio padrão aproximadamente $0,5 \mathrm{~m}$, representando menos de $0,2 \mathrm{mGal}$ na medida de g (McLintock et al., 1994). Note-se que a incerteza na medida da altimetria, de muito supera as demais envolvidas no cálculo da propagação de erros.

Para a execução das medidas de altimetria por barometria foram utilizados 4 altímetros analógicos marca Thommen dois altímetros digitais Intellisensor modelo “Air-DB”. Para a correção da medida devido à umidade do ar, utilizaram-se dois psicrômetros de aspiração da marca "Iope", munidos de dois termômetros, sendo um com bulbo seco e o outro umedecido. Na base permaneceram um altímetro Thommen, dois altímetros digitais Air-DB e um psicrômetro, ficando os demais no conjunto do instrumental para as medidas itinerantes. Na base as leituras foram feitas em intervalos de 15 min, de forma a permitir uma interpolação confiável para fins de correção das medidas itinerantes.

Todas as medidas de altimetria foram referidas à Rede de Nivelamento do IBGE, tomando-se como base os pontos RN-2120-V (altitude: 29,3112 m; coordenadas: -47 50'38" long e $-24^{\circ} 29^{\prime} 30^{\prime \prime}$ lat). Não houve necessidade de transferência da base, uma vez que a distância máxima entre esta e a medida mais afastada foi inferior a $30 \mathrm{~km}$, e o máximo desnível entre as RNs de referência e os pontos sobre o perfil não ultrapassou $300 \mathrm{~m}$.

\section{Características físicas das rochas}

Para fins de modelagem do corpo, foram determinadas densidades através das ondas sísmicas (presente trabalho) e medidas em amostras de áreas vizinhas (Slavec et al., 2001); foram também utilizadas suscetibilidades de algumas amostras da cobertura sedimentar (Tabela 1).

\section{PROCESSAMENTO E MODELAGEM DOS DADOS GEOFÍSICOS}

Para o processamento das imagens do Landsat 5, utilizouse o programa Er-Mapper versão 6.3 da Geosoft. A representação fornecida ( $384 \times 384$ pixels) foi mantida, resultando nas Figuras $2 \mathrm{a}$ e $2 \mathrm{~b}$ após a composição das bandas citadas acima.

Para fins da representação da anomalia aeromagnética, os dados fornecidos pela CPRM, sobre uma malha equiespaçada, foram reduzidos para o mesmo modelo do geóide utilizado na determinação das coordenadas UTM e adequados para sua utilização no programa SURFER v. 7.0 (Golden Software, 2000). Através desse programa foi obtida a imagem do campo magnético anômalo da região em relevo com um ângulo de iluminação de $45^{\circ} \mathrm{NW}$ (Figura 1a).

Em vista da característica dipolar da anomalia magnética na latitude em que se encontra, foi aplicada a redução ao pólo 
Tabela 1. Densidades e suscetibilidades medidas para amostras coletadas na área de estudo e vizinhanças, para diferentes litologias. R - Presente trabalho. J - Slavec et al. (2001). * - densidades estimadas pelas velocidades sísmicas. Susceptibilidades características obtidas em literatura (Telford et al., 1990).

\begin{tabular}{cccccc}
\hline $\begin{array}{c}\text { Longitude } \\
(\mathbf{m})\end{array}$ & $\begin{array}{c}\text { Latitude } \\
(\mathbf{m})\end{array}$ & $\begin{array}{c}\text { Densidade } \\
\left(\mathbf{g} / \mathbf{c m}^{\mathbf{3}}\right)\end{array}$ & $\begin{array}{c}\text { Suscetibilidade } \\
\left(\times \mathbf{~ 1 0}^{\mathbf{3}}\right) \mathbf{s I}\end{array}$ & Litologia & Ref. \\
\hline 225.703 & 7.282 .124 & $1,9^{*}$ & 0,213 & Sedimento & $(\mathrm{R})$ \\
225.445 & 7.283 .022 & $1,8^{*}$ & 0,183 & Sedimento & $(\mathrm{R})$ \\
224.017 & 7.283 .719 & $1,5^{*}$ & 0,048 & Conglomerado & $(\mathrm{R})$ \\
228.450 & 7.206 .720 & 2,7 & $0,1-25$ & Gnaisse & $(\mathrm{J})$ \\
226.180 & 7.293 .930 & 2,85 & $30-40$ & Sienito & $(\mathrm{J})$ \\
228.000 & 7.298 .000 & $3,16^{*}$ & 125 & Piroxenito & $(\mathrm{R})$ \\
\hline
\end{tabular}

considerando-se a inclinação $\left(I=-45^{\circ}\right)$ e o azimute $(N 10 \mathrm{~W})$ da época do levantamento. A anomalia monopolar resultante apresenta intensidade da ordem de $2400 \mathrm{nT}$. A localização da anomalia reduzida ao pólo coincide com a anomalia gravimétrica e com a estrutura oval, subcircular, observada nas imagens do Landsat 5. Sua modelagem é descrita mais adiante.

A modelagem dos dados gravimétricos sobre o perfil levantado utilizou a anomalia Bouguer residual, obtida após subtrair o campo regional calculado por ajuste polinomial de grau 2 através do método de mínimos quadrados. $\mathrm{O}$ mesmo procedimento foi aplicado às medidas magnéticas terrestres levantadas ao longo do mesmo perfil, obtendo-se a anomalia magnética residual. Os valores de anomalias residuais foram projetados sobre o perfil AB (Figura 1b) e interpolados de forma a que fossem todos eqüidistantes. Esse conjunto de pontos foi utilizado para fins de modelagem buscando o melhor ajuste dos dois sinais simultaneamente, com geometria 2,5 D utilizando o programa GRAVMAG (Pedley et al., 1997).

Como parâmetros do modelo inicial, consideraram-se: a profundidade do topo do corpo a $40 \mathrm{~m}$ da superfície; a densidade dos sedimentos superficiais $\left(1,7 \mathrm{~g} / \mathrm{cm}^{3}\right)$, com base nas velocidades das ondas sísmicas; a densidade do corpo intrusivo $\left(3,14 \mathrm{~g} / \mathrm{cm}^{3}\right)$, compatível com aquela dos corpos alcalinos situados nas vizinhanças e a densidade da rocha encaixante $\left(2,67 \mathrm{~g} / \mathrm{cm}^{3}\right)$ equivalente à média da crosta continental superior.

O melhor ajuste obtido é apresentado juntamente com o corte vertical do corpo e rochas adjacentes sob o perfil na Figura 6. O posicionamento dos ensaios sísmicos que confirmaram a presença do topo do corpo está assinalado como círculos cheios. Observa-se um relevo irregular para o topo do corpo chegando, em alguns pontos, próximo da superfície. Nas laterais, entre a encaixante e o corpo intrusivo
( 2 em preto), a definição de zonas de alteração e/ou hidrotermalização ( 3 e 4 em cinza; 1,9 a 2,67 g/ $/ \mathrm{cm}^{3}$ ) permitiu refinar o ajuste. A profundidade máxima do corpo "alcalino" resulta $1 \mathrm{~km}$.

Diante da distribuição espacial da anomalia aeromagnética, definida por 5 linhas de vôo, procedeu-se à modelagem 3D da anomalia residual, apresentada sob forma de contorno na Figura 1b, e reduzida ao pólo. Para tal utilizouse o programa de cálculo IGMAS (Göetze e Lahmeyer, 1988) considerando-se como parâmetros iniciais $9 \mathrm{~A} / \mathrm{m}$ para o contraste de magnetização entre a intrusão e a rocha encaixante e a profundidade máxima do topo de $1 \mathrm{~km}$. O programa cria " $n$ " perfís paralelos (eqüiespaçados) e os ajusta simultaneamente a cada alteração de qualquer parâmetro especificado. A anomalia calculada sobre a malha formada pelos pontos ao longo dos perfis é comparada com aquela medida, e através de uma análise estatística são calculados o desvio padrão, o coeficiente de correlação, volume e distribuição de massa.

Na modelagem foram utilizados 17 perfis entre as latitudes 7281,4 e 7284,6 km e o melhor ajuste obtido apresentou um resíduo máximo inferior a $100 \mathrm{nT}$, um desvio padrão de $87 \mathrm{nT}$ com coeficiente de correlação de $97 \%$ (Figura 7).

O corpo resultante está representado em $3 \mathrm{D}$ na Figura 8a, sendo o volume total estimado em $10,5 \mathrm{~km}^{3}$, equivalente a aproximadamente $3,3 \times 10^{12} \mathrm{~kg}$ (ou $3,3 \times 10^{9} \mathrm{t}$ ). Considerando-se a distribuição de massa sob forma de isópacas de contorno (Figura 8b), pode-se apreciar melhor a estrutura do corpo. Note-se que neste caso não estão sendo levados em consideração os refinamentos introduzidos no modelo gravimétrico $2,5 \mathrm{D}$, como pode ser visto através da secção vertical do perfil de mesmas coordenadas de AB (Figura 9a), e do correspondente gravimétrico sem refinamento (Figura $9 b$ ). 


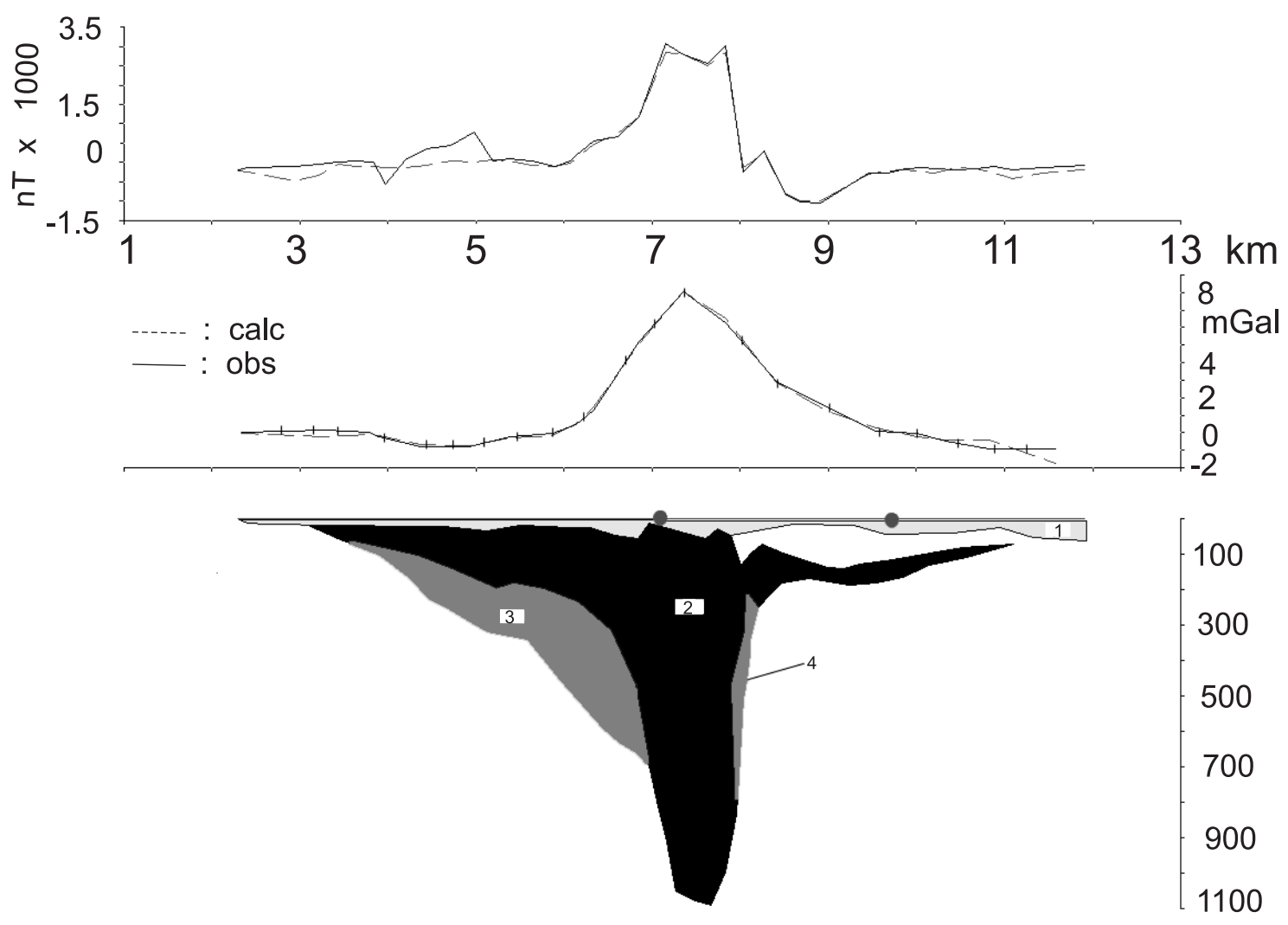

$(\mathrm{m})$

Figura 6. Modelagem com geometria 2,5D dos dados gravimétricos e magnéticos levantados ao longo do perfil que cruza a anomalia. Os dados foram projetados sobre o perfil $A B$ e interpolados de forma a serem eqüidistantes. Os dados coletados foram subtraídos dos respectivos campos regionais de forma a modelar apenas o campo anômalo residual. Para a modelagem foi utilizado o programa de cálculo GRAVMAG que, ao se mudarem as coordenadas dos vértices ou propriedades como densidade ou susceptibilidade, calcula diretamente a anomalia produzida pelo(s) corpo(s) - método direto. A linha contínua corresponde aos dados originais interpolados; a linha tracejada à resposta dos corpos modelados. Na porção inferior da figura observa-se secção vertical do corpo sob o perfil, e suas prováveis variações litológicas. Os parâmetros utilizados são descritos no texto. Os dois círculos cheios em superfície fornecem a localização das sondagens sísmicas. 

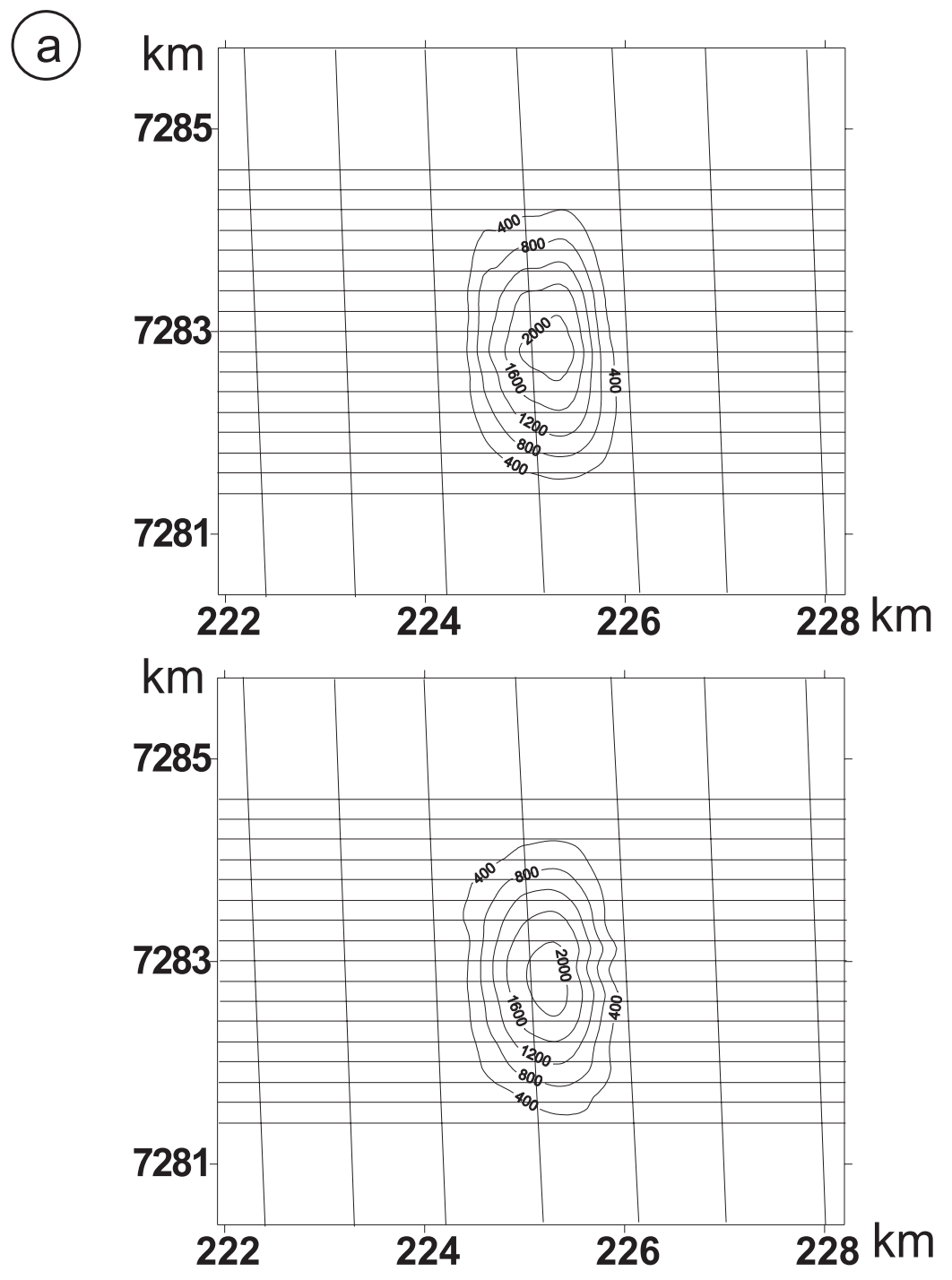

Figura 7. Representação em superfície da anomalia residual reduzida ao pólo (acima) e daquela calculada pelo programa IGMAS (abaixo). As linhas N-S, observadas na figura são as linhas de vôo do levantamento aéreo, e as linhas E-W a posição dos planos utilizados na modelagem. O histograma resulta da análise estatística e representa a distribuição das discrepâncias entre o campo real e aquele modelado, sendo o desvio padrão de 87 nT e o coeficiente de correlação de $97 \%$.

(b)

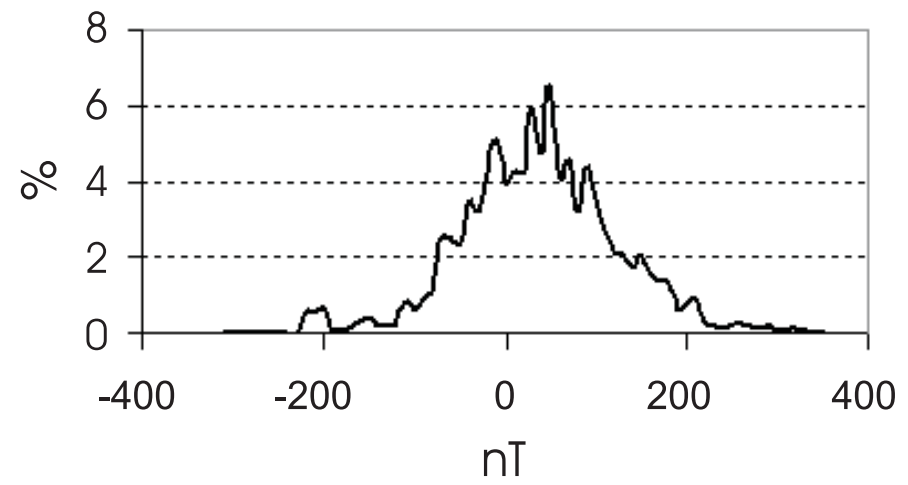


(a)

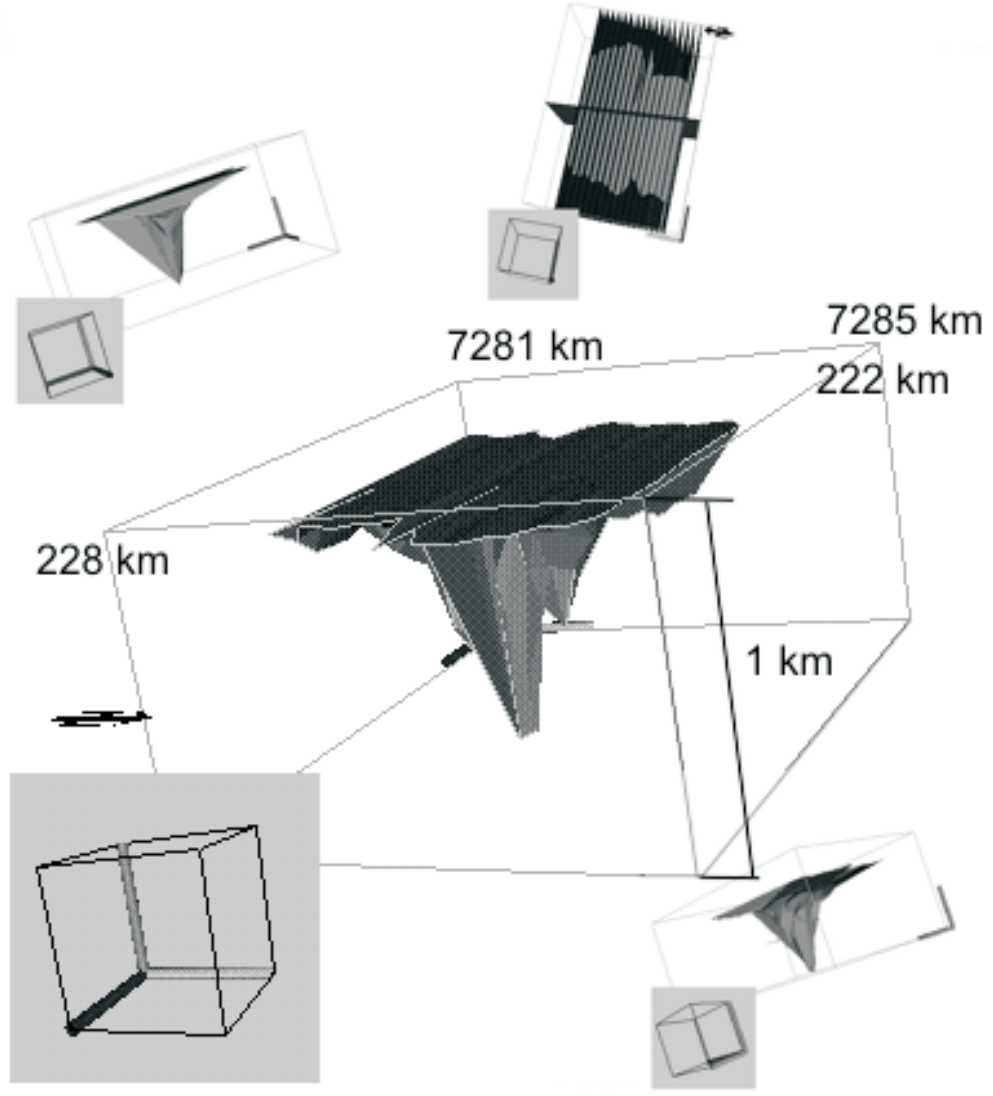

(b)

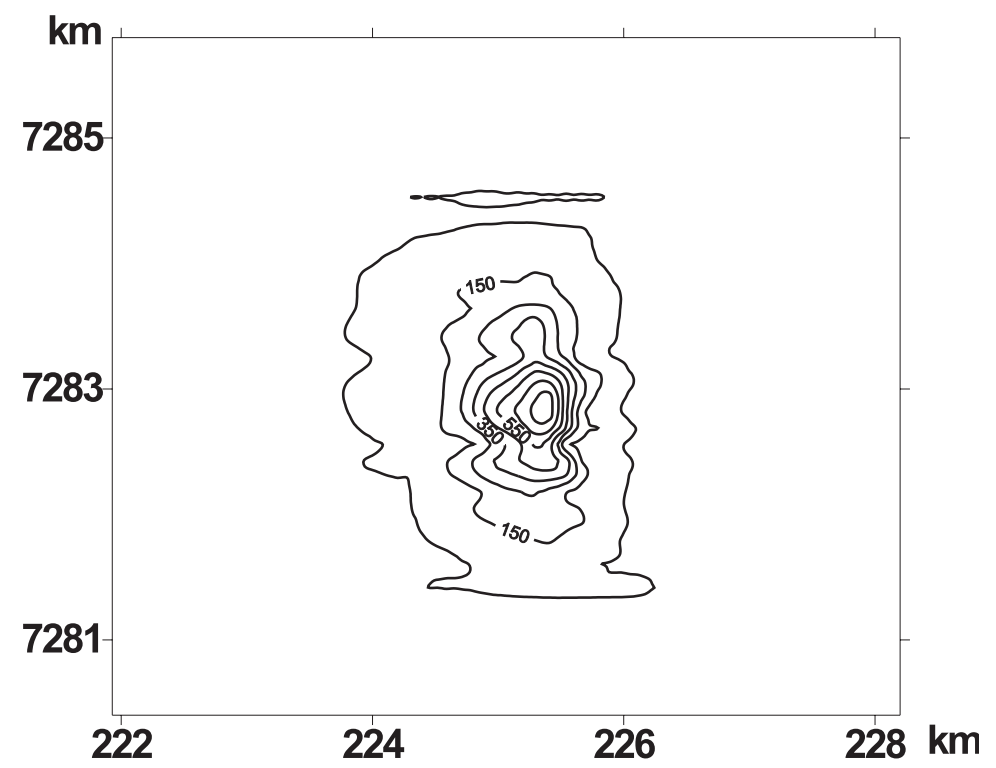

Figura 8. a) Representação do corpo modelado em 3D com exagero vertical de 2,28. Os parâmetros estão descritos no texto. Na figura maior, central, observa-se o detalhe do corpo em perspectiva E-W. Nas figuras menores ele é rotacionado relativamente à maior. Na figura menor superior é mostrada a configuração dos planos (cortes) utilizados na modelagem. b) Representação da espessura do corpo (ou distribuição de massa) por isópacas com intervalos de $100 \mathrm{~m}$. 

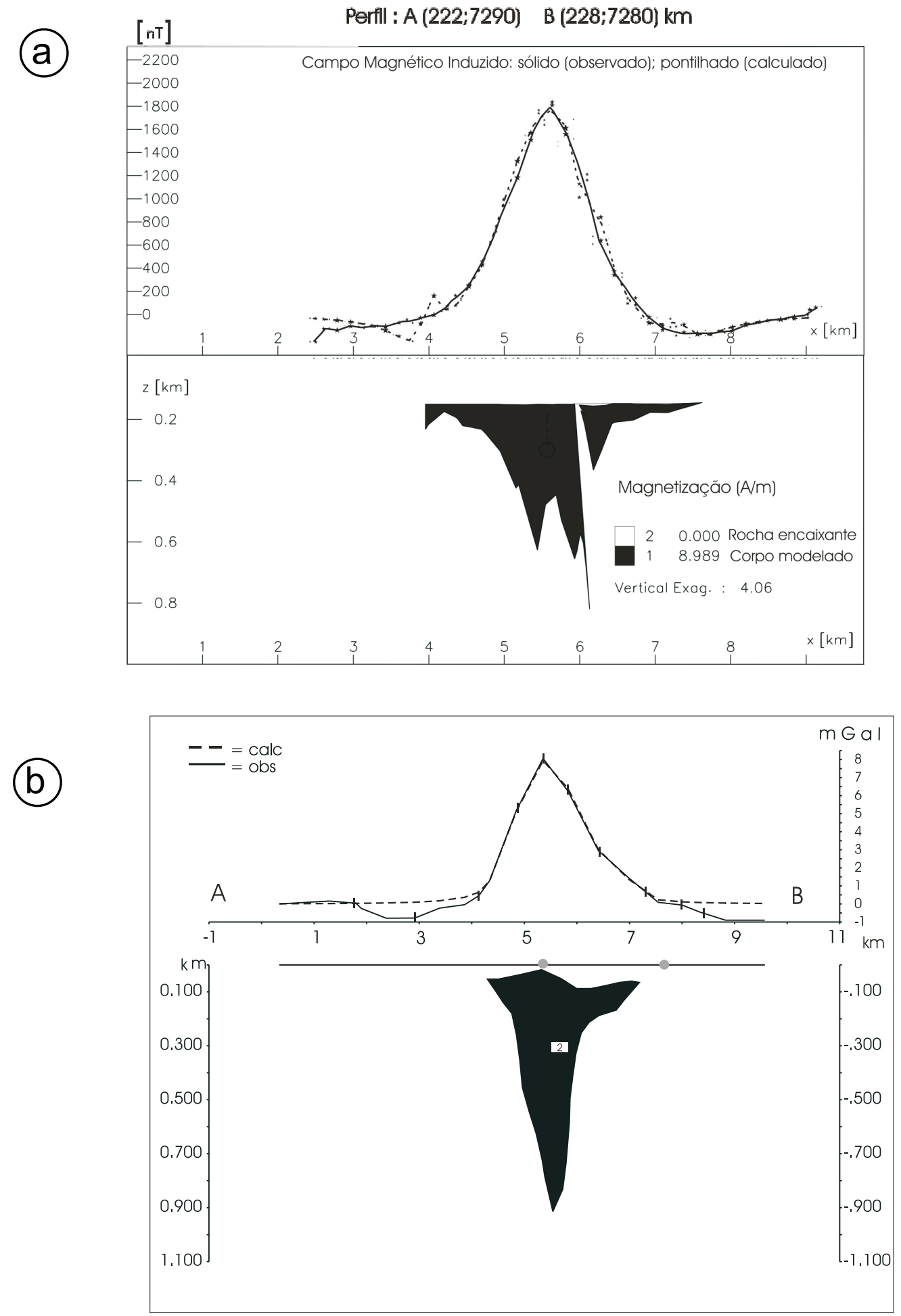

Figura 9. a) Perfil $A B$ extraído do campo da anomalia aeromagnética reduzida ao pólo e sua comparação com (b) aquela gravimétrica modelada para uma única litologia. Nas duas figuras observa-se o ajuste entre a anomalia real e aquela modelada; a profundidade é semelhante; a diferença na forma lateral é devida à diferença na resposta litológica aos dois campos (magnético e gravimétrico). Os parâmetros estão descritos nas figuras e no texto. Os dois círculos sólidos correspondem à localização das sondagens sísmicas. 


\section{CONCLUSÕES}

As várias técnicas geofísicas aplicadas à área compreendida entre as coordenadas UTM (SAD69, meridiano central $\left.-45^{\circ}\right)[221,7277]$ e $[230,7288] \mathrm{km}$, contribuíram para definir a forma e dimensões de uma intrusão com características de magmatismo alcalino, responsável pela anomalia magnética de Registro.

Com base na análise das refrações observadas nos registros sísmicos coletados foi possível obter uma estimativa pontual para a profundidade do topo do corpo no local em que foram realizados os ensaios, bem como estimar uma provável densidade para a camada de sedimentos. Esses parâmetros aliados a medidas de susceptibilidade e dados de densidades obtidos em laboratório e in situ, constituíram os vínculos principais para o modelo inicial nas modelagens 2,5D e 3D.

A modelagem 2,5D utilizou o ajuste simultâneo dos sinais gravimétrico e magnético terrestre sobre um mesmo perfil, e resultou num corpo de espessura máxima de $1 \mathrm{~km}$ e com topo irregular próximo da superfície $(<40 \mathrm{~m})$. O refinamento do modelo, que proporcionou um melhor ajuste aos dados geofísicos, sugere que no contato com a intrusão ocorreram processos hidrotermais provocando, localmente, uma redução na densidade da rocha encaixante.

A modelagem 3D, possível apenas através dos dados aeromagnéticos permitiu estimar a geometria e o volume do corpo, que associado à densidade de aproximadamente $3,14 \mathrm{~g} / \mathrm{cm}^{3}$ compatível com aquela e corpos alcalinos situados nas vizinhanças, possibilitou estimar sua massa em $\cong 3,3 \times 10^{9} \mathrm{t}$.

A grande contribuição dos métodos geofísicos para este problema é a caracterização de uma intrusão de possível interesse econômico, que não apresenta manifestações geológicas em superfície, e a metodologia que consistiu em associar várias técnicas para reduzir as ambigüidades no processo inverso.

\section{AGRADECIMENTOS}

Aos Sr. Eduardo Moraes Leite e Sra. Elaine Loureiro pelo apoio de campo; aos Drs. Carlos Alberto Mendonça pelo empréstimo dos magnetômetros e Ginaldo Campanha pela cessão dos dados de imagem de satélite (LANDSAT 5); à CPRM pela cessão dos dados do aerolevantamento SP-RJ; ao IBGE pela permissão de uso do banco de dados de RNs; ao ON pela permissão de uso do bancos de dados da rede gravimétrica fundamental brasileira; e finalmente, ao CNPq pelo imprescindível apoio financeiro. Queremos também agradecer aos dois revisores João Carlos Dourado e Augustinho Rigotti que muito contribuíram para o aprimoramento do texto.

\section{REFERÊNCIAS BIBLIOGRÁFICAS}

ALMEIDA, F. F. M. Relações tectônicas das rochas alcalinas mesozóicas da região meridional da Plataforma Sulamericana. Revista Brasileira de Geociências, v. 13, p. 139-158, 1983.

AMARAL, G. Potassium-argon age studies on the Jacupiranga alkaline district, State of São Paulo, Brasil. In: INTERNATIONAL SYMPOSIUM ON CARBOnAtites, 1., 1978, Poços de Caldas. Proceedings... Brasília: DNPM, 1978. p. 297-302.

AMARAL, G.; BUSHEE, J.; CORDANI, U. G; KAWASHITA, K.; REYNOLDS, J. H. Potassium-argon ages of alkaline rocks from southern Brazil. Geochimica et Cosmochimica Acta, v. 31, n. 2, p. 117-142, 1967.

ANJOS, I. L. S.; MOURÃO, L. M. F. Projeto São Paulo-Rio de Janeiro. In: COMPANHIA DE PESQUISA DE RECURSOS MINERAIS. Relatório final: processamento dos dados. S.1.: 1988. p. 1-29.

BORN, H. O complexo alcalino de Juquiá. 1971. 177 p. Tese (Doutorado) - Instituto de Geociências, Universidade de São Paulo, São Paulo, 1971.

CÉRMAK, V.; HUCKENHOLZ, D. Landolt-Bornstein: zahlenwerte und funktionen aus naturwissenschaft und techinik. Berlin: Springer Verlag, 1982. 373 p.

GARDNER, G. H. F.; GARDNER, L. W.; GREGORY, A. R. Formation velocity and the diagnostic basics for stratigraphic traps. Geophysics, v. 39, p. 770-780, 1974.

GEMAEL, C. Introdução à Geodésia Física. Curitiba: Editora da UFPR, 2002.302 p.

GOLDEN SOFTWARE. Advanced digitizing solutions: DIDGER user manual. Colorado, Golden Software, 2000. $185 \mathrm{p}$

GÖTZE, H. J.; LAHMEYER, B. Application of three: dimensional interactive modeling in gravity and magnetics. Geophysics, v. 53, n. 8, p. 1096-1108, 1988.

GOMES, C. B.; CORDANI, U. G. Geocronologia do maciço alcalino de Itapirapuã, São Paulo. Anais da Academia Brasileira de Ciências, v. 37, n. 3, p. 497-501, 1965.

GOMES, C. B.; LAURENZI, M.; CENSI, P.; DEMIN, A.; VELASQUEZ, V.F.; COMIN-CHIARAMOTI, P. Alkaline magmatism from Northern Paraguay (Alto Paraguay): a Permotriassic Province. In: COMIN-CHIARAMONTI, P.; GOMES, C. B. (Ed.). Alkaline magmatism in CentralEastern Paraguay: relationships with coeval magmatism in Brazil. São Paulo: Edusp: Fapesp, 1996. p. 223-230.

FERREIRA, F. J. F.; ALGARTE, J. P. O comportamento aeromagnético-cintilométrico das principais rochas alcalinas dos Estados de São Paulo e Paraná. In: SIMPÓSIO REGIONAL DE GEOLOGIA, 2., 1979, Rio Claro. Anais... Rio Claro: SBG-SP, 1979. v. 2, p. 195-208.

LONGMAN, I. M. Formulas for computing the tidal 
accelerations due to the Moon and the Sun. Journal of Geophysical Research, v. 64, p. 2351-2355, 1959.

MCLINTOCK, D.; DEREN, E. J.; KRAKIWSKY, E. J. Environment sensitive: DGPS and barometry for seismic surveys. GPS World, v. 6, n. 2, p. 20-26, 1994.

MORBIDELLI, L.; GOMES, C. B.; BECCALUVA, L.; BROTZU, P.; CONTE,A. M.; RUBERTI, E.; TRAVERSA, G. Mineralogical, petrological and geochemical aspects of alkaline and alkaline-carbonatite associations from Brazil. Earth Sciences Review, v. 39, n. 3-4, p. 135-168, 1995.

PEDLEY, R. C.; BUSBY, J.P.; DABEK, Z. K. GRAVMAG user manual: interactive $2.5 \mathrm{D}$ gravity and magnetic modeling. Keyworth: British Geological Survey, 1997. 73 p. (Technical Report, WK/93/26/R).

SLAVEC, G. B.; MANTOVANI, M. S. M.; SHUKOWSKY, W. Contribuição ao estudo do Complexo de Juquiá. Revista Brasileira de Geociências, v. 31, n. 2, p. 203-210, 2001.

TELFORD, W. M.; GELDART, L. P.; SHERIFF, R. E.; KEYS, D. A. Applied geophysics. Cambridge, UK: Cambridge University Press, 1990.860 p. 